\title{
Single solar cell ideality factor determination using a fixed point method
}

\author{
Traiki Ghizlane ${ }^{1}$, Ouajji Hassan ${ }^{1}$, Bifadene Abdelkader ${ }^{1}$, Bouattane Omar ${ }^{1}$ \\ ${ }^{1}$ Laboratory of Signals, Distributed Systems and Intelligence Artificial, ENSET Mohammedia \\ Hassan 2 University, Casablanca
}

\section{Article Info}

Received Aug 1, 2018

\author{
Keyword: \\ Ideality factor \\ Fixed point \\ Solar cell
}

\begin{abstract}
The modeling and extraction of solar cell parameters are the crucial steps for simulating and optimizing the photovoltaic systems to meet specific properties. These parameters are directly related to the current-voltage characteristic of the solar cell under illumination, the latter is generally represented, by an equivalent electrical circuit whose parameters (the shunt resistance, the saturation current, the series resistance and the ideality factor of the diode) have been the subject of several researches. This paper describes an iterative algorithm based on fixed point method to calculate the ideality factor of a photovoltaic cell. The procedure uses the electrical and mathematical equations governing the solar cell behavior. The obtained results were compared to the previous works to show its effeteness.
\end{abstract}

\section{Corresponding Author:}

Traiki Ghizlane,

Laboratory Signals, Distributed Systems and Intelligence Artificial, ENSET Mohammedia, BP.159 Mohammedia Principale, Morocco

Email: traiki.ghizlane@gmail.com

\section{Introduction}

In the literature, there are several models of photovoltaic cells whose purpose is to obtain the current-voltage characteristic I-V for the analysis and performance evaluation of photovoltaic modules [19]. The electrical model with a diode is the most commonly used, as well as two resistors series Rs and shunt Rp respectively associated to the circuit [1] [18]. This model makes it possible to determine the parameters of the solar cell such as the ideality factor of the diode " $n$ " which depends on the polarization voltage. It gives us information on the origin of the current flowing in the junction and the quality of the material, this factor depends on the atomic interaction of the metal-semiconductor interface. It describes the excess of recombination in the depletion zone [2]. The ideality factor is about 1 for an electron diffusion mechanism [17]. When the two currents are comparable for the silicon diodes, it is between 1 and 2. If it takes other values, it means that other mechanisms occur for the transport of the current. The increase of the ideality factor of the diode causes the decrease of the maximum power point in the operating zone.

In recent years, several methods have been developed to determine the ideality factor of solar diodes. From these methods we distinguish: the direct measurement method of " $n$ " from the JV light output curve has been proposed in [3], the use of the special trans-function theory commonly called STFT that allows the solving of transcendent equations [4] and "The Lambert W function method" for which the measurements are carried out under dark conditions [15]. The diode ideality factor known as the quality factor [5], is an indispensable parameter in the description of the photovoltaic cells behavior. 
The purpose of this study is to determine an optimal value of the ideality factor " $n$ " using an iterative method based on the fixed point technique to solve the current-voltage equation, the method is applied to a simplemathematical model illustrated in figure 1. The proposed method has been tested on MATLAB / Simulink software, the obtained result were compared to some previous ones.

This paper is organized as follows: Section 2 is devoted to the fixed point method and it application for our case context. Section 3 presents some simulation results and discussion to show the obtained ideality factor of a sample of a grey solar cell studied in [14]. The final section 4 gives some concluding remarks.

\section{Fixed point method}

\subsection{Presentation}

Iterative process is a fundamental principle in computer science. It is generally used to find equations roots, solutions of nonlinear equations and differential equations, and so.

The fixed point method applied to solve nonlinear equations of the form $\mathrm{F}(\mathrm{x})=0$. It consists to elaborate an iterative scheme, in this case a convergent sequence towards a fixed point $\mathrm{x}$ of a certain application $\mathrm{g}$, this fixed point is in this case the solution of the equation $\mathrm{F}(\mathrm{x})=0$.

Given an equation: $\mathrm{F}(\mathrm{x})=0$, the fixed point method is defined as follows:

1. Convert the equation to the form $\mathrm{x}=\mathrm{g}(\mathrm{x})$.

2. Start with an initial guess $\mathrm{x}_{0} \approx \mathrm{r}$, where $\mathrm{r}$ is the actual solution of the equation.

3. Iterate, using $\mathrm{x}_{\mathrm{n}+1}:=\mathrm{g}\left(\mathrm{x}_{\mathrm{n}}\right)$ for $\mathrm{n}=0,1,2, \ldots$

Fixed point technique is one of the methods to solve nonlinear equations. As an example of complex nonlinear equations translating some physical behaviours, is the one studied in [6]. In this case, the equation is formulated as: $\mathrm{B}=\mu \mathrm{H}+\mathrm{R}$, and $\mathrm{H}=\nu \mathrm{B}+\mathrm{I}$, where $\mathrm{R}$ and $\mathrm{I}$ are the nonlinear residual terms determined iteratively. In our case of the exploitation of the totality of current-voltage measurements coming directly from a PV module, the equation (1) is analyzed to be solved by the fixed point method to sort out the ideality factor of the component

In this paper, we propose another method to solve nonlinear equation (1), since, other methods used to find ideality factor seem to be complicated to implement directly. An example of those used in" STFT" [4] and" W-function" [15].

\subsection{Application to the solar cell model}

In this section, we will present iterative method used to solve non linear equations in aim to find an optimal value of diode ideality factor. Several equivalent circuits have been proposed in the literature to design the behavior of the photovoltaic cell ([7], [8], [9], [10]). In [9], the authors used meta-heuristic methods: teachinglearning-based optimization (TLBO) and simple teaching-learning-based optimization (STLBO) for constrained mechanical design optimization problems. This technique identifies the unknown parameters in the nonlinear solar cell models. It is characterized by a fewer adjustable parameters and requires no more parameters, except the population size and the number of iteration. In [7], biogeography-based optimization (BBO) is used to identify the optimal estimation parameters of both solar and fuel cells. BBO algorithm incorporates the mutation motivated from the differential evolution (DE) algorithm, it produce solutions of high quality and has fast convergence rate. In [8], the method applied is Pattern Search (PS) which is able to solve a wide range of optimization problems. This technique is used to minimize the error associated with the estimated solar cell parameters. The technique used in [10] is an optimization method based on meta-heuristic approach particle swarm optimization (PSO) which has a higher expectation to obtain a global solution in comparison with deterministic ones heuristic methods. This algorithm evokes mechanism forces premature convergence.

In our case, we consider the model to be a diode of Figure 1 and implemented the fixed point method to find its ideality factor. 


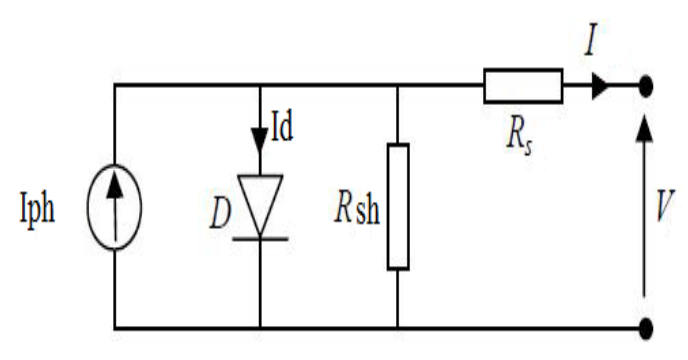

Figure 1. Electrical equivalent model of the photovoltaic cell.

The mathematical model of a real solar cell, under lighting and for normal operating conditions, consists of a series resistor and a shunt resistor. Its current-voltage characteristic (I-V) is given by:

$$
I=I_{p h}-I_{0}\left(e^{\frac{V+R_{S} I}{n V_{t h}}}-1\right)-\frac{V+R_{S} I}{R_{s h}}(1)
$$

Where:

$I_{0}:$ saturation current in the diode.

$n$ : the junction ideality factor $(1<n<2)$.

I: supplied current by the cell when it operates as a generator.

$V$ : voltage at the terminals of this same cell.

$I_{p h}$ : the cell photo-current dependent on the illumination and the temperature.

$R_{s h}$ : shunt resistance characterizing the junction leakage currents.

$R_{s}:$ series resistor representing the various contacts and connections resistances.

$V_{\text {th }}$ : thermal voltage: $V_{t h}=\frac{K T}{q}$

K: Boltzmann constant $\left(1.38110^{-23} \mathrm{~J} / \mathrm{K}\right)$.

T: cells effective temperature in Kelvin $\left({ }^{\circ} \mathrm{K}\right)$.

$q$ : the electron charge $\left(q=1.610^{-19} \mathrm{C}\right)$.

Equation (1) is non-linear, it includes the overall output current produced by the solar cell in both sides of the equation. This equation does not have explicit analytical solution for current or voltage. In fact, different numerical optimization methods have been used to solve such equations. The well known ones are: the graphical analysis method [11], the Newton-Raphson method [12], the polynomial method from Levenberg Marquardt [13], and so...

Such an equation, (1) can be rewrited as follows:

$$
F(I)=I_{p h}-I_{0}\left(e^{\frac{V+R_{S} I}{n V_{t h}}}-1\right)-\frac{V+R_{S} I}{R_{s h}}(2)
$$

$$
\mathrm{Y}=\mathrm{I}-\mathrm{F}(\mathrm{I})
$$

The fixed point method consists in creating an iterative scheme, in which case the sequence tends to a fixed point characterized by a steady state that gives $\mathrm{I}=\mathrm{F}(\mathrm{I})$. This fixed point is remains the solution of the solar cell current equation (1).

The proposed method is implemented using the well known model of the grey solar cell parameters of [14]. Table 1 presents these characteristics. 
Table 1.Grey solar cell parameters [14].

\begin{tabular}{cc}
\hline Parameter & Grey solar cell \\
\hline $\mathrm{V}_{\mathrm{oc}}(\mathrm{V})$ & 0.524 \\
$\mathrm{R}_{\mathrm{s}}(\mathrm{m} \Omega)$ & 77.69 \\
$\mathrm{R}_{\mathrm{sh}}(\Omega)$ & 25.9 \\
$\mathrm{I}_{0}(\mathrm{~mA})$ & 5.514 \\
$\mathrm{I}_{\mathrm{ph}}(\mathrm{A})$ & 0.5610 \\
$\mathrm{~V}_{\mathrm{th}}(\mathrm{mV})$ & 26.479 \\
\hline
\end{tabular}

\section{Simulation results and discussion}

In order to determine the ideality factor we set the problem as:

Find the point meeting $\mathrm{I}=\mathrm{F}(\mathrm{I})$ for different values of $\mathrm{n}$.

Using an iterative process, figure 2.a shows the corresponding curve for each value of $n$.

Figure 2.b represents a zooming area around the point $(0,0)$ which is the solution meeting $\mathrm{I}$ and $\mathrm{F}(\mathrm{I})$. This solution corresponds to a particular ideality factor we are looking for.

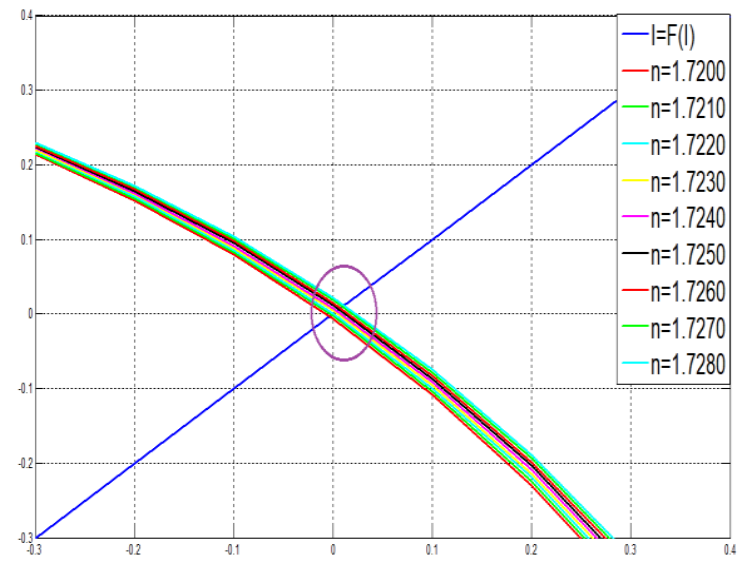

Figure 2.a. Evolution of $\mathrm{y}=\mathrm{I}-\mathrm{F}(\mathrm{I})$ for a variable ideality factor

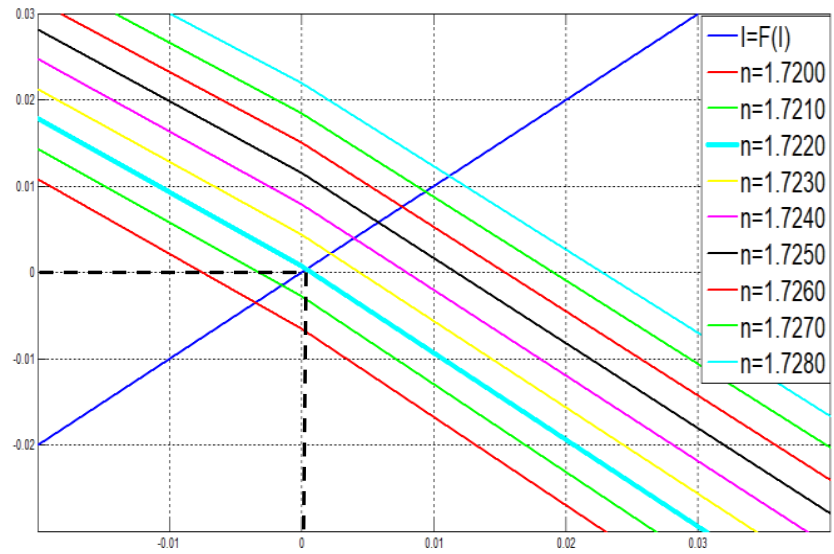

Figure 2.b. Intersection of curves with $\mathrm{F}(\mathrm{I})=\mathrm{I}$ in the zoom area

This iterative method, which solves nonlinear equations, requires extensive computation and also good approximations to converge. This method gives a clear and understandable solution to the current-voltage 
equation (1). Figure 2.b illustrates a set of the current-voltage characteristics for different ideality factors (small variations). The cell current gradually increases as a factor of ideality of the diode decreases. As shown in figure $2 . b$ the solution converges to point 0 for an ideality factor $n=1.7220$.

Table 2 shows a comparison between the value of the ideality factor obtained by the fixed point method and the other methods.

Table2. Different ideality factor value using analytic and iterative methods.

\begin{tabular}{ccccc}
\hline Cell type & $\begin{array}{c}\text { STFT } \\
\text { solution[4] }\end{array}$ & $\begin{array}{c}\text { Fixed point } \\
\text { method }\end{array}$ & $\begin{array}{c}\text { Analytical } \\
\text { solution [15] }\end{array}$ & $\begin{array}{c}\text { W-function } \\
\text { solution[16] }\end{array}$ \\
\hline Grey solar cell & 1.7217 & 1.7220 & 1.7225 & 1.7270 \\
\hline
\end{tabular}

The proposed algorithm is illustrated in figure 3, where the iterative process is presented. It shows that the obtained solution is acceptable and it is similar to those of previous works.

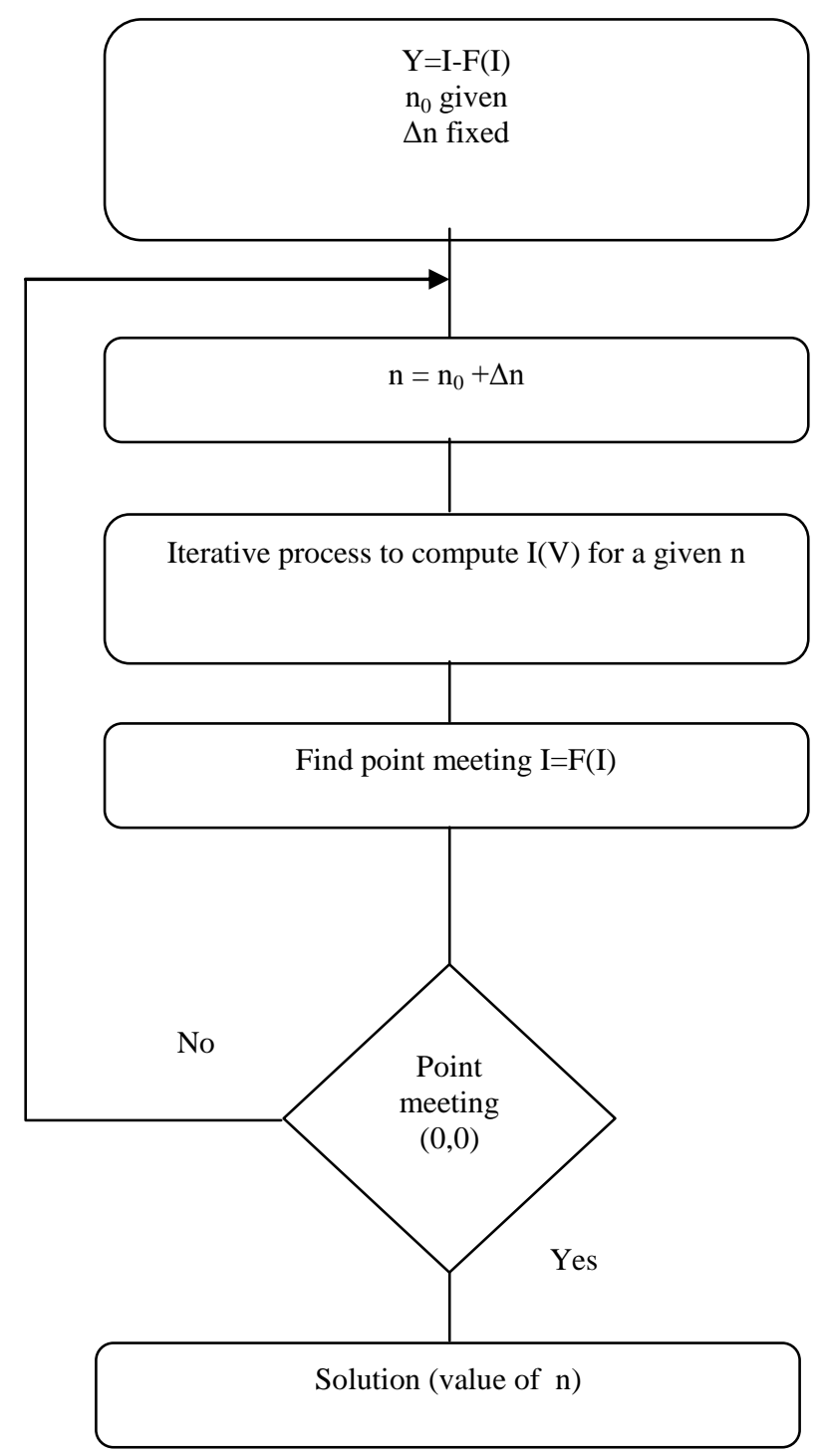

Figure 3. Determination diode ideality factor optimal value. 


\section{Conclusion}

In this work, we applied an iterative and effective method for implicit equation, to determine the optimal value of the diode ideality factor for an electrical model to five parameters. We obtained a reasonable value of "n" which is slightly similar to those in literature. The right choice of the ideality factor leads to a better aptitude of the I-V and P-V characteristics of the solar cells and obtains a representation closer to the real MPP (Maximum Power Point) of the solar modules. The optimal value of $\mathrm{n}$; helps the physicists to develop the powerful solar cells, some technical solution such as the MPPT (Maximum Power Point Tracker) must be added to the solar plant converter to improve the total efficiency of the system. MPPT improves the efficiency of the conversion of photovoltaic systems. It is able to help PV cells to achieve more power efficiently and provide electricity to the grid.

\section{References}

[1] F.Harashima, H.Inba, Seijikondo, and N.Takashima, "Microprocessor-Controlled SIT Inverter For Solar Energy System". IEEE Transactions On Industrial Electronics, Vol IE-34, no 1, February 1987, pp 5055.

[2] S.Min Sze. "Semiconductor Devices: Physics and Technology". Wiley. 2nd Edition. 2008, pp 50-129.

[3] J.Quanxi and L.Enke. "A method for the direct measurement of the solar cell junction ideality factor". Solar Cells, 22 (1987), pp $15-21$.

[4] N.Santakrus Singh, A.Jain and A.Kapoor. "Determination of the solar cell junction ideality factor using special trans function theory (STFT)". Solar Energy Materials \& Solar Cells 93 ,2009, pp 1423-1426.

[5] Y.J.Maa, I.M.Abdel-Motaleb, "Analysis of the diode characteristics using the thermodynamic theories". Solid-state Electron, vol. 46, 2002, pp 735-742.

[6] F.Ossart, V. Ionita."Convergence of the modified fixed-point method in magnetic field problems with hysteresis". The European Physical Journal Applied Physics, Vol. 5, Issue 1, January 1999, pp 63-69.

[7] Q.Niu, L.Zhang, K.Li. "A biogeography-based optimization algorithm with mutation strategies for model parameter estimation of solar and fuel cells". Energy Convers Manage, Vol.86, 2014, pp 1173-85.

[8] M.F.AlHajri, K.M.El-Naggar, M.R.AlRashidi, A.K.Al-Othman. "Optimal extraction of solar cell parameters using pattern search". Renewable Energy, Vol.44, 2012, pp 238-245.

[9] Q.Niu, L.Zhang, K.Li. "An improved TLBO with elite strategy for parameters identification of PEM fuel cell and solar cell models". International Journal Hydrogen Energy, Vol.39, 2014, pp 3837-3854.

[10] D.Oliva, E.Cuevas , G. Pajares. "Parameter identification of solar cells using artificial bee colony optimization". Energy, Vol.72, 2014, pp 93-102.

[11] A.Oueriagli, H.Kassi, S.Holchandani and R.M.Leblanc. "Analysis of Dark Current-Voltage Characteristics of $\mathrm{Al} / \mathrm{chlorophyll} \mathrm{a/Ag} \mathrm{Sandwich} \mathrm{Cells".} \mathrm{Journal} \mathrm{of} \mathrm{Applied} \mathrm{Physics,} \mathrm{Vol.} \mathrm{71,} \mathrm{№11,}$ 1992, pp 5523 - 5530.

[12] WH.Press, WT.Vettering and SA.Teukolsky. "Numerical Recipes in C: The Art of Scientific Computing", 2nd Ed. Cambridge University Press, Vol. 9, 2002, pp 362 - 367.

[13] D. Marquardt. "An Algorithm for Least Squares Estimation of Nonlinear Parameters". SIAM Journal of Applied Math, Vol. 11, 1963 pp 431 - 441.

[14] J.P.Charles, M.Abdelkrim, "A pratical method of analysis of the current-voltage characteristics of solar cells".Solar Cells, Vol.4, 1981, pp 169-178.

[15] X.Gao, Y.Cui, J.Hu, G.Xu, Y.Yu. "Lambert W-function based exact representation for double diode model of solar cells: comparison on fitness and parameter extraction". Energy Conversion and Management, Vol.127, 2016, pp 443-460.

[16] A.Jain and A.Kapoor. "A new method to determine the diode ideality factor of real solar cell using Lambert W-function". SolarEnergy Mater and Solar Cells, Vol.85, 2005, pp 391-396.

[17] E.Çetin YILMAZ, M.Kaan YEŞILYURT, İ.Volkan ÖNER, G.ÖMEROĞLU, A.Numan ÖZAKIN. "Operational Stability and Degradation of Organic Solar Cells".Periodicals of Engineering and Natural Sciences.Vol.5, N², June 2017, pp 152-160.

[18] E.Kandemir, Numan S. Cetin, S.Borekci. "A Comparison of Perturb \& Observe and Fuzzy-Logic Based MPPT Methods for Uniform Environment Conditions".Periodicals of Engineering and Natural Sciences. Vol.5, $\mathrm{N}^{\circ} 1$ (2017), pp 16-23. 
[19] M.MWANZA, J.CHACHAK, Numan S. ÇETIN, K.ÜLGEN. "Assessment of Solar Energy Source Distribution and Potential in Zambia". Periodicals of Engineering and Natural Sciences. Vol.5, N², June 2017, pp 103-116. 